\title{
DOCÊNCIA MASCULINA E MEMÓRIAS DE GÊNERO NA EDUCAÇÃO DA INFÂNCIA
}

\author{
AdRIANA HORTA DE FARIA \\ MAGDA SARAT \\ Universidade Federal da Grande Dourados (UFGD), Dourados, Mato Grosso \\ do Sul, Brasil \\ Larissa Wayhs TREIN MONTIEL \\ Universidade Federal de Mato Grosso do Sul (UFMS), Naviraí, Mato Grosso \\ do Sul, Brasil
}

\begin{abstract}
Resumo: 0 objetivo deste artigo é verificar e analisar as implicações do conceito de gênero na trajetória docente de um professor que lecionou para crianças, em um espaço que se constituiu majoritariamente como feminino ao longo do século XX. A opção metodológica foi a História Oral temática, produzindo uma documentação a partir das memórias desse professor. As memórias de sua trajetória docente serão analisadas à luz das teorias de Norbert Elias e bibliografia da temática. Tais perspectivas nos permitem apontar que no espaço escolar percebemos redes de dependência, interdependência e poder sempre presentes nas relações de gênero, envolvendo os docentes e suas trajetórias profissionais.
\end{abstract}

Palavras-chave: Homens professores. Trajetória Docente. História Oral. Norbert Elias.

\section{INTRODUÇÃO}

O primeiro ano foi bem difícil! Você é acostumado de um jeito e aí... aquela molecada!(Prof. Derci)

A trajetória profissional de todo indivíduo não é um processo linear, mas está envolvido em avanços, retrocessos e rupturas que marcam sua trajetória. Portanto, ao falar da do cência estamos evocando um indivíduo que vivencia esses processos e procura encaminhá-lo fazendo a história possível. Dito isso, apresentamos nosso professor, pela epígrafe acima, demostrando um indivíduo que, para além de seu ofício de ensinar as crianças a ler, escrever e a contar, também tinha que lidar com suas emoções, comportamentos, rever suas práticas e se reinventar profissionalmente todos os dias.

A figura do professor enfatiza um indivíduo que tem origens, formação familiar, valores, crenças e princípios que determinam suas trajetórias, tanto de vida como de formação profissional. Portanto, nesse espaço estão inscritas sua formação inicial, seus antigos mestres, as condições geográficas e econômicas do seu contexto social, e neste recorte acrescentaremos seu sexo e gênero como referências significativas para o proces- 
so de constituição de sua profissionalidade docente. 0 profissional docente traz na trajetória de vida e de formação todas as marcas das relações sociais estabelecidas no grupo social que o constitui como um processo de interdependência com os outros indivíduos deste grupo. Tomamos aqui o conceito elisiano de interdependência para compreender como as relações se estabelecem.

(...) planos e ações, impulsos emocionais e racionais de pessoas isoladas constantemente se entrelaçam de modo amistoso ou hostil. Esse tecido básico, resultante de muitos planos e ações isolados, podem dar origem a mudanças e modelos que nenhuma pessoa isolada planejou ou criou. Dessa interdependência de pessoas surge uma ordem sui-generis, uma ordem mais irresistível e mais forte do que a vontade e a razão das pessoas isoladas que a compõem. É essa ordem de impulsos e anelos humanos entrelaçados, essa ordem social, que determina o curso da mudança histórica (ELIAS, 1993, p. 194).

Para Norbert Elias, estamos envoltos em uma rede de ações que nos ligam mutuamente um ao outro, pelas próprias relações de dependência entre nós, formando uma complexa trama de relações, permitindo um processo de interdependência entre os indivíduos, que vai além da nossa simples vontade ou desejo de mudança ou manutenção dos processos vivenciados. Portanto, relações de interdependências geram figurações, para Elias, tomadas como grupos de pessoas com vínculos específicos e móveis. Esse padrão pode ser aplicado a pequenos ou grandes grupos como os professores de uma escola ou os indivíduos que compõem um país (ELIAS, 2005).

Tal discussão é importante pois desejamos apontar o lugar do docente, do professor, dentro das figurações de que ele faz parte. Destacamos que, para Elias, dentro dessas figurações existem "o modelo de jogos", ou seja, regras, padrões e normas que constituem os indivíduos enquanto grupo e determinam a distribuição do poder entre eles. Nesse contexto, todos os indivíduos, componentes de uma figuração, se movimentam de acordo com necessidades e interesses, provocando tensões que são parte da organização social dos grupos. Assim, o poder inscrito no interior do grupo circula e se movimenta como uma 'balança', definida pela posição do jogo, em movimentos independentes da vontade do jogador. Portanto, se equilibrar à medida que o pêndulo da balança vai definindo gradientes de poder. Para Norbert Elias $(2005$, p.81),

Nas relações entre pais e filhos e entre senhor e escravo, as oportunidades de poder são distribuídas muito desigualmente. Porém sejam grandes ou pequenas as diferenças de poder, o equilíbrio de poder está sempre presente onde quer que haja uma interdependência funcional entre pessoas. Sob esse ponto de vista, a utilização simples do termo "poder" pode induzir em erro. Dizemos que uma pessoa detém grande poder, como se o poder fosse uma coisa que se metesse na algibeira. Esta utilização da palavra é uma relíquia de ideias mágico-míticas. O poder não é um amuleto que um indivíduo possua e outro não; é uma característica estrutural das relações humanas — de todas as relações. 
FARIA, A. H.; SARAT, M.; MONTIEL, L. W. T.

Nessa perspectiva pretendemos estudar as memórias de professores aposentados, buscando discutir e propor uma reflexão também para os processos de formação de novos professores, de modo a contribuir com as pesquisas acerca da história da prática docente. Elemento fundamental na articulação de memórias, histórias de vida, no sentido de "alicerçar-se numa reflexão na prática e sobre a prática, através das dinâmicas de investigação-ação e de investigação-formação, valorizando os saberes de que os professores são portadores e intimamente ligados com as práticas educativas" (NÓVOA, 1991, p.64). Tais ações levam a investigar e propor dinâmicas que podem levar a "construir novos quadros teóricos de referência articulando harmoniosamente saberes acadêmicos com as epistemologias das práticas docentes" (NÓVOA, 1991, p.64).

Buscamos perceber a educação em sua complexidade, evidenciando as possibilidades concretas do espaço escolar contribuir para a superação das desigualdades culturais de gênero, contemplando a atuação masculina na docência com crianças, como apontamos anteriormente, um espaço majoritariamente feminino. Assim, sugerimos que as masculinidades e as feminilidades possam ser entendidas como construções sociais que variam de acordo com o espaço (uma cultura para outra), com o tempo (numa mesma cultura, através do tempo), ao longo da vida de cada pessoa nas relações mantidas nos grupos sociais a partir de aspectos como classe, raça, grupo etário, étnico, entre outros.

Neste sentido, para este artigo, apresentamos um recorte de uma pesquisa mais ampliada, que pretende tomar os aspectos de gênero envolvidos no percurso de vida e trajetória profissional de indivíduos, buscando evidenciar como os lugares sociais são construídos de modo a definir as identidades de homens e mulheres atuando como instrumentos de hierarquização, exclusão e poder entre os indivíduos e seus grupos.

\section{DOCÊNCIA E GÊNERO: 'MODELOS' PARA HOMENS E MULHERES}

A comunidade escolar, pautada no senso comum, muitas vezes encara com estranhamento o fato de ter homens atuando como professores de crianças. Desse modo, eles são identificados pelos adultos como "impacientes", "desajeitados", ou ainda "brutos", que podem oferecer "ameaça física ou sexual". Os professores homens são vistos pelas crianças, especialmente em contextos da educação infantil, como 'parceiros', 'amigos'.

Essas concepções simplórias também forjaram uma ideia de que as mulheres são consideradas as mais indicadas para trabalhar com crianças, pois elas possuem características 'natas' do universo feminino, como a delicadeza, a paciência, a meiguice, a sensibilidade e, principalmente a aproximação com a maternidade. No entanto, autores da temática nos informam que tais mitos e percepções precisam ser discutidos e revistos nos contextos da educação das crianças. Entre eles citamos: SAYÃO (2005), CARVALHO (1998), RABELO (2013), RAMOS (2011), FARIA; GONÇALVES (2016), SARAT; CAM POS (2017).

Essas concepções arraigadas em nosso grupo social procedem por estarmos imersos em um modelo no qual "a civilização que estamos acostumados a considerar como uma posse que aparentemente nos chega pronta e acabada, sem que perguntemos como viemos a possuí-la, é um processo ou parte de um processo em que nós estamos envolvidos" (ELIAS, 1993, p.73). Portanto, precisamos nos desvencilhar de determinadas formas de organização e problematizar nossas perspectivas. 
A história da educação escolar brasileira aponta que os primeiros a ocupar a profissão docente, atuando inclusive com crianças, foram os homens. Eles estavam à frente da escolarização desde os jesuítas e depois, no período pombalino, com o afastamento destes missionários, foram implantadas ações na direção de manter essa docência dirigida por professores (LOURO, 2012).

Mais tarde, com o advento da educação para as mulheres nos finais do século XIX e a abertura de novos mercados de trabalho para os homens, a profissão docente começou a migrar para um território de formação feminina, com a criação das primeiras escolas normais para meninas. A profissão docente foi uma das principais ocupações da mulher, principalmente no magistério primário para atuação com crianças pequenas. No nível secundário e superior ainda predominava à docência masculina.

Nesse contexto, uma porção significativa dos homens que lecionavam para crianças se voltou na busca de outros empregos com melhor remuneração, acompanhando o desenvolvimento industrial do país e sua consequente modernização no início do século XX. Somado a isso, recaía sobre os homens os valores de uma cultura patriarcal, na qual, considerados os responsáveis por suprir todas as necessidades econômicas da família, não poderiam fazê-los com os baixos rendimentos da docência (LOURO, 2012; DERMATINI; ANTUNES, 1993; TAMBARA, 1998; NÓVOA, 1991).

As mulheres passam a assumir a posição deixada pelos homens na carreira docente se consolidando ao longo do século XX como uma profissão de mulheres, pois "à medida que os homens foram sendo convocados para trabalhar na industrialização recém-inaugurada na América Latina e já consolidada na Europa, os postos de trabalho docente foram sendo relegados às mulheres" (SARAT, 2015, p. 29).

Esse processo, aparentemente naturalizado, é resultado de um período de longa duração histórica na qual as transformações se constituem a partir do que Elias aponta como um processo no qual os grupos vão configurando lugares para homens, mulheres e crianças em todas as sociedades. Dentre esses modelos sociais destacamos os que configuram concepções em torno da regulação e do controle da sexualidade, da reprodução, da divisão sexual do trabalho, tanto nos âmbitos públicos como privados. Esses modelos de comportamento perpassam a educação e suas formas de organização.

A educação como um processo social que nos interessa no momento, se insere nessas transformações das relações de gênero na qual existem modelos de idealização para homens e mulheres, legitimando uma perspectiva discriminatória e limitada. Homens e mulheres vivenciam modelos construídos socialmente, que se perpetuam no contexto da escola, em uma relação de poder em desequilíbrio. Portanto, o conceito de gênero, numa perspectiva relacional, é fundamental para a compreensão do debate que nos desafia cotidianamente, pois conforme elaborado por Scott (1998, p. 15):

Gênero é a organização social da diferença sexual. Ele não reflete a realidade biológica primeira, mas ele constrói o sentido desta realidade. A diferença sexual não é a causa originária da qual a organização social poderia derivar; ela é, antes, uma estrutura social móvel que deve ser analisada nos seus diferentes contextos históricos. 
FARIA, A. H.; SARAT, M.; MONTIEL, L. W. T.

Assim, tais premissas nos instigam a compreender que sexo é apenas uma diferença biológica, enquanto gênero, por sua vez, é uma construção social e histórica que fundamenta a distinção e a relação entre o feminino e o masculino. Compreendemos também que os estudos de gênero incluem outras dimensões como o sistema político, as relações de poder, os vínculos sociais de dependência e interdependência entre outros.

Nessa perspectiva, os estudos de gênero se expandiram incluindo no debate a construção das masculinidades, e, sobre a temática, Robert (agora Rayween) Connell (1987), uma das precursoras destes estudos, defende que é preciso investir na produção de conhecimento sobre a temática "masculinidades" como estratégia para o enfrentamento das questões pertinentes às relações de gênero.

Desse modo, em consequência dos estudos desenvolvidos com homens, utilizamos o termo "masculinidades" compreendendo o conceito como resultado de interações sociais dos homens com os demais indivíduos, e como expressões da dimensão relacional de gênero (que apontam expressões, desafios e desigualdades). As masculinidades são configurações de práticas sociais, que se dão no controle das emoções, na ideologia, na cultura, nas instituições, enfim, nas convenções sociais. Para Connell (1987) e Connell e Messerschmidt (2013), as masculinidades estão atreladas a várias estruturas, em diferentes trajetórias históricas. Não têm um padrão fixo e podem ser alteradas de acordo com o tempo, espaço e culturas entre si e dentro de padrões variáveis. Um mesmo grupo social, comunidade ou instituição, pode possuir diferentes padrões de masculinidade, ou modos de se tornar homem e se conceber o masculino.

\title{
HISTÓRIAS DE VIDA E TRAJETÓRIAS DA PESQUISA
}

A lembrança do professor foi a nossa fonte documental. Realizamos a entrevista, que se apoiou na memória desse indivíduo e naquilo que emergia do seu passado, reconstruindo-o como um exercício de manter-se vivo e existir socialmente no presente. Trabalhamos com a memória, entendida para além da capacidade humana de conservar e transmitir as produções materiais e intelectuais produzidas em diferentes tempos e espaços, mas percebemos a memória como possibilidade de colocar em evidência indivíduos, vivências e trajetórias que podem contribuir com seu grupo.

\begin{abstract}
A memória permite a relação do corpo presente com o passado e, ao mesmo tempo, interfere no processo "atual" [...]. Pela memória, o passado vem à tona das águas presentes, misturando-se com as percepções imediatas, como também empurra, "desloca" estas últimas, ocupando espaço todo da consciência. A memória aparece como força subjetiva ao mesmo tempo profunda eativa, latente e penetrante, oculta e invasora (BOSI, 1994, p. 46-47).
\end{abstract}

Assim, optamos por trabalhar com a história oral e suas infinitas perspectivas teórico-metodológicas, entendendo também como uma prática social que gera mudanças e transformam tanto o conteúdo quanto a finalidade da história (Thompson, 1992). Propõe mudanças incidindo sobre o passado dos indivíduos, particularmente na esfera do cotidiano e daquilo que, em geral, não consta em documentos escritos. Portanto, percebemos a história oral como "possibilidade de [...] valorizar todos aqueles que sejam representados nas pesquisas e investigações, valorizando vozes de pessoas, 
trajetórias de vidas, memórias, biografias, histórias que possam dar respostas aos nossos questionamentos" (SARAT e SANTOS, 2010, p. 50-51).

Ao apontar as memórias de professores e suas lembranças do passado, desenvolvemos uma atividade árdua no sentido que lembrar não é algo espontâneo, mas sim uma volta ao passado e "a maior parte das vezes, lembrar não é reviver, mas refazer, reconstruir, repensar, com imagens e ideias de hoje, as experiências do passado. A memória não é sonho, é trabalho" (BOSI, 1994, p. 55).

Refazer percursos e falar do trabalho está inerente aos que já saíram do processo produtivo, como é o caso do entrevistado, um professor aposentado que, ao contar sua experiência profissional e trajetória de formação, revive aspectos do trabalho desenvolvido, em determinado período, e o sentido dos seus feitos pedagógicos, pois "a memória do trabalho é o sentido, é a justificação de toda uma biografia" (BOSI 1994, p. 481). Por meio da biografia de professo res buscamos compreender a história da profissão docente a partir da contribuição de seu olhar engajado socialmente.

Um último aspecto da história da pesquisa refere-se à memória como parte de um entrelaçamento relacional. Refere-se às redes que estabelecemos ao longo da vida, que nos permitem vivenciar coletivamente experiências que nos individualizam e nos tornam um grupo. Nesse processo de interdependência entre indivíduos e grupos, localizamos os indivíduos que participaram da pesquisa, pois eles mantiveram contato em seus grupos coletivos, e assim foi possível perceber tais redes de relacionamento. Assim, obedecendo todos os procedimentos metodológicos, técnicos, éticos da pesquisa com história oral, pudemos ouvir a história pessoal focando os aspectos de sua escolarização na infância, seu processo de formação profissional, suas experiências de atuação e, finalmente o tempo presente pós aposentadoria. Aprendendo que "o historiador oral, segundo ensinam, é aquele que se dispõe a ouvir, ouvir e ouvir" (SARAT, 2004, p. 117).

\section{MEMÓRIAS DO VIVIDO: GÊNERO E CONCEPÇÃO DOCENTE MASCULINA}

Iniciamos com a trajetória do professor Derci como docente desde o ano de 1977, no município de Iguatemi, localizado no extremo sul do estado de Mato Grosso do Sul, na fronteira com o Paraguai. Trabalhou por mais de três décadas e se jubilou ocupando cargo na gestão da educação no município de Naviraí, em 2010. Sua infância foi na cidade de Nhandeara, em São Paulo, onde, órfão de mãe, foi adotado ao nascer por um casal e teve mais cinco irmãos. No mesmo município, cursou o primário em escola rural e o colegial na cidade. Em busca de melhores condições de trabalho a família migrou para o estado do Paraná, onde seu pai foi trabalhar com madeira e ele, já rapaz, foi estudar o ensino médio profissionalizante no curso de magistério, não por escolha pessoal:

Não foi uma escolha, na época só tinha o magistério para cursar, eu entrei e daí três meses inauguraram a escola de contabilidade, quem queria passar do magistério para contabilidade podia mudar, mas eu falei: Não! Eu faço de manhã o magistério e 
FARIA, A. H.; SARAT, M.; MONTIEL, L. W. T.

matriculei à noite no "contador", e durante o período que ficava vago eu ajudava na serraria, no escritório (DERCl, 2017).

O professor Derci relata que cursou o magistério e o curso de contabilidade. Nesse período, a valorização da educação tecnicista preconizava o Ensino Técnico Profissional Contábil - Decreto-Lei no 6.141/43 - (BRASIL, 1943). A legislação, em acordo com a proposta pelo governo da época, investia na modalidade com o objetivo de formar profissionais para desempenhar atividades no comércio, efetuar transações financeiras, e exercer funções de caráter administrativo acerca dos negócios.

Os homens foram a maioria dos estudantes do curso técnico contábil, e ainda hoje eles figuram predominantemente nos cursos das Ciências Sociais Aplicadas e Exatas (CARVALHO; RABAY, 2013; CRUZ, 2012). É conveniente ressaltar que, historicamente, esta tendência está presente nas propostas curriculares que priorizavam para os meninos as disciplinas de matemática, oferecendo estímulos que ainda têm marcas na educação profissional.

Sobre o curso de magistério, o professor Derci conta que: "Nessa época[por volta de 1974] era mais mulher, quando eu comecei só tinha eu e outro aluno" (2017). As primeiras instituições para formação de professores foi a escola normal, que originalmente foi destinada aos homens e começa a receber um grande número de mulheres, já no início do período republicano, e a presença feminina foi aumentando até se tornar uma escola quase exclusivamente feminina (LOURO, 2012; TANURI, 2000).

A partir de 1971, período que precede a carreira do professor Derci, foi promulgada a Lei n. 5.692/1971, em plena vigência da ditadura militar, quando é possível perceber reformas no âmbito da educação e a educação técnica passa a ser prioridade. A Escola Normal passou a ser chamada Habilitação para o Magistério, tornando-se um curso de nível médio e frequentado em maioria exclusiva por mulheres. Inicialmente os cursos de pedagogia eram bacharelados que formavam "técnicos em educação" (VINCENTINI; LUGLI, 2009, p.54).

Esse período, que passa a indicar maior incidência feminina nos cursos, tem um histórico que precede a formação feminina que sempre foi relegada aos espaços domésticos, destinada ao cuidado da casa e dos filhos. No entanto, esse cenário começa a mudar à medida que, no processo civilizador, há uma superação desses modelos, provocando alterações na balança de poder e nas relações entre grupos onde 0

afloramento de tensões é permanente, provavelmente porque aceitar-se como eles implica em posição secundária no acesso às fontes de poder. Pensar conjuntamente o eu, o nós e o eles constitui o grande desafio sociológico, especialmente por termos aqui uma relação entre grupos com diferenciais de poder acentuados (GEBARA, 2011, p.61).

A pesquisa nos indica que, no estado de Mato Grosso, tais tensões estavam presentes, bem como a concepção do trabalho feminino apontado em alguns documentos, ao justificar a aptidão das mulheres para atuar no magistério. 0 inspetor de instrução pública, Dermevil J osé dos Santos Malhado, utilizou os seguintes argumentos: 


\begin{abstract}
A mulher tem qualidades especiais para educadora e mestras; é muito superior ao outro sexo em clareza, doçura, imaginação, paciência, bondade, zelo e graça, o que constitui para com as crianças, sempre saudosas do carinho materno, uma espécie de atração para a professora, sujeitando-se elas as imposições do estudo, unicamente para satisfazê-la (PROVÍNCIA DE MATO GROSSO. Inspetoria Geral. Relatório de 1880, p. 8).
\end{abstract}

0 registro corrobora a percepção corrente do período e remete às professoras a tarefa de educar, partindo do pressuposto de que atributos considerados socialmente femininos seriam suficientes na profissão. Tal perspectiva em comparação atribuiria ao professor homem um perfil de mestre-escola rígido, zangado, divergindo da imagem da professora delicada e preocupada com os alunos. Nesse aspecto, Louro (2012), aponta que a inserção das mulheres como professoras no mercado de trabalho passou a ser vista como uma extensão da maternidade:

\begin{abstract}
Afirmavam [...] elas são as primeiras e 'naturais educadoras'. [...] Se o destino primordial da mulher era a maternidade bastaria pensar que o magistério representava, de certa forma, uma 'extensão da maternidade', cada aluno ou aluna vistos como filho ou filha 'espiritual' (LOURO, 2012, p. 450).
\end{abstract}

A concepção corrente, de que a mulher poderia estender para o espaço público as atividades desenvolvidas no espaço privado, se estenderá pela formação do trabalho das profissionais que atuam com crianças, criando dilemas e desafios na formação docente, especialmente para a professora de criança nos níveis de educação infantil e inicial. Em outro trabalho apresentando dados de Brasil e Argentina acerca da formação docente, percebemos que "nesses países o trabalho de atendimento às crianças pequenas era feito em geral por mulheres, a grande maioria sem formação e firmada nos conceitos maternal e biológico, ou seja, bastava ser mulher e mãe para ter estar habilitada a trabalhar com criança” (SARAT, 2015, p. 28). Tal situação contribuiu para a estabilização e precarização do trabalho docente, provocando afastamento dos homens e aumentando o movimento de feminização do magistério no Brasil.

Retornando ao professor Derci, ele narra que seu ingresso no magistério se deu de modo ocasional, em função de uma visita aos pais no município de Iguatemi/MS. 0 fato de ter o curso de Magistério veio a público provocando sua entrada na profissão docente, pois a diretora da única escola da cidade ao saber que ele tinha formação o convidou:

Eu morava em São Paulo. Meu pai vendeu tudo e foi para Iguatemi/MS, eu vim passear e naquela época não existia professor formado. A diretora não me deixou sair eu voltei (em São Paulo) peguei as minhas coisas e vim embora para Iguatemi/MS e comecei a dar aula. Eu era formado e ia ganhar cinco vezes mais do que eu ganhava na gráfica, então eu vim! (DERCl, 2017).

O período, meados dos anos de 1970, indica que havia uma grande carência de formação adequada para atuação docente nas áreas rurais, representando um entrave em 
todo o estado de Mato Grosso, em especial na região Sul (FURTADO; MOREIRA, 2015). Tratando-se da zona rural, o recrutamento era feito geralmente entre os próprios moradores da localidade e as pessoas consideradas letradas, ou com maior formação, assumiam a tarefa de lecionar às crianças as primeiras letras.

Nesse período, especialmente considerando Mato Grosso e suas áreas rurais, algumas iniciativas foram tomadas para a profissionalização dos professores, entre eles os cursos "Normal de Férias" (PIACENTINI, 2015). O professor Derci lecionou no curso e tal aspecto representa a mudança e o deslocamento de poder nas relações estabelecidas entre ele e suas colegas de profissão. Pelo fato de ter formação concluída, ele, que era subordinado à direção e à vice direção, passa a ser professor delas no curso. Conforme relata: "a diretora era mulher e a vice-diretora, mas não tinham magistério, nem nada! Quando inaugurou a escola veio o curso do magistério, e eu fui dar aula no magistério para elas, porque elas queriam formar no magistério" (DERCl, 2017).

Ao afirmar que o poder está inscrito nas relações sociais, Norbert Elias (2005) ensina que podemos percebê-lo nas mudanças presentes nas diversas figurações das quais fazemos parte. No fato narrado pelo professor Derci percebemos que o pêndulo da 'balança de poder' era variável, aumentando ou diminuindo seus gradientes à medida que esses indivíduos mudavam sua posição na relação cotidiana estabelecida por eles, sendo ele como professor, ela como gestora e, ainda, ele como professor e ela como aluna.

Assim, entendemos o poder como relacional e presente nos processos de interdependências vividos em distintas figurações, nas quais o mesmo indivíduo se relaciona de forma heterogênea, exercendo espaços de poder distintos. Na figuração escolar em que o professor Derci esteve envolvido no início da sua carreira, ele apresenta ainda a perspectiva das relações com as crianças nas práticas cotidianas, sendo ele um professor homem convivendo com a educação das crianças, conforme relata:

No primeiro ano trabalhei segunda série, na época crianças com oito anos, nove anos. Você pegava praticamente analfabeto, começando nas letras, tinha aluno que não sabia nada! Você sai de um negócio, eu trabalhava em gráfica e ir para uma sala de aula e lidar com criança, foi difícil! A criança você tem que ter um jogo de cintura para tratar ela e é pequena... (DERCI, 2017).

Esse frag mento demonstra a dificuldade do professor no início e a consciência de que seria uma tarefa árdua, pois historicamente, e de modo privado, a educação das crianças pequenas sempre esteve a cargo das mulheres, o que explicava 0 fato do professor não ter nenhuma experiência. No entanto, se falarmos de trabalho profissional, consideramos que os primeiros anos de atuação de um professor, independente de sexo ou gênero, pode ser considerado um período de "sobrevivência", de "descoberta".

O aspecto da "sobrevivência" traduz o que se chama vulgarmente de "choque do real", a confrontação inicial com a complexidade da situação profissional [...] Em contrapartida, o aspecto da "descoberta" traduz o entusiasmo inicial, a experimentação, a exaltação por estar finalmente em situação de responsabilidade (ter a sua sala de aula, os seus alunos, o seu programa, por se sentir colega num determinado corpo profissional) (HUBERMAN, 2007, P. 28). 
O professor Derci vivenciou esse momento de tentar 'sobreviver' junto às crianças, até adaptar-se e 'descobrir' a profissão, embora no seu relato reconheça que o trato com crianças maiores tornava a tarefa mais fácil. 0 professor relata que nos anos seguintes as professoras atuavam com $1^{\underline{a}}$ e e $2^{\underline{a}}$ séries, e os professores homens, $3^{3}$ e e $4^{\underline{a}}$ séries, ou seja, crianças maiores que já não exigiam muito cuidados por parte do professor e foi feita uma divisão para priorizar tal aspecto. Essa possível 'aptidão feminina' com crianças menores é parte da nossa cultura, atribuindo às mulheres essa tarefa e usando 0 argumento do 'instinto maternal' (SAYÃO, 2005).

0 professor Derci atuou por três anos com as crianças e, após graduar-se em Estudos Sociais, passou a exercer a profissão nos anos finais do chamado 1 o grau e no 20 grau, ministrando disciplinas de História, Filosofia, OSPB (Organização Social e Política do Brasil), Sociologia, Geografia e Educação Moral e Cívica. Com oportunidade de progressão de carreira, trabalhou ainda em cargos de gestão por mais de dez anos, e nessa posição finalizou sua carreira docente, por ele descrita da seguinte maneira:

Segui a carreira normalmente. Eu comecei no segundo ano e fui passando pegando os maiores, mas é melhor você trabalhar com adolescente e adultos do que de você trabalhar com criança, é muito melhor! Por que o segundo grau tem uma outra visão, o adolescente, oitava série é diferente, depois fui para a gestão e foi normal (DERCl, 2017).

Ao retratar sua trajetória, dá ênfase na atuação com adolescentes e jovens, e aponta as dificuldades de trabalhar com crianças, apontando um caminho recorrente nas experiências do magistério masculino: o fato de alçar para a gestão da escola ou da instituição. Sua história é semelhante à dos docentes pesquisados por Pincinato (2007), apontando que os homens são mais propensos a alcançar cargos hierárquicos.

Na nossa sociedade o modelo masculino é formado por valores e significados que estão, na maioria das vezes, relacionados ao poder, à autoridade e ao prestígio social. Por outro lado, constatou-se por meio dos estudos da História do Magistério, que valores femininos atribuídos à ocupação se deve, em muito, à ideologia da vocação e do cuidado da criança, devido à associação feita entre o exercício do magistério e a condição de mãe (PINCINATO, 2007, p.162).

Nesse contexto, podemos perceber que, na trajetória do nosso professor, a escola manteve a perspectiva de reproduzir estereótipos de gênero que estão presentes na sociedade, afirmando espaços de masculinidades e feminilidades. Aos homens estão relacionadas as posições de autoridade, onde parecem mais adequados e adaptáveis, como se fosse um curso natural da sua formação. Além disso, a gestão escolar é um cargo que agrega maior prestigio social (status), remuneração, privilégios e, consequentemente, poder sobre a instituição e seus subordinados. Para alguns homens essa seria uma oportunidade de se aproximar do modelo de masculinidade proposta socialmente, ou seja, ocupar uma posição superior entre outros homens e mulheres. No caso das mulheres, as feminilidades nesse ambiente estariam voltadas à ideia de vocação e cuidado com as crianças, como extensão da maternidade e da submissão a um diretor 
FARIA, A. H.; SARAT, M.; MONTIEL, L. W. T.

homem como o líder e o condutor da instituição (PINCINATO, 2007; CONNELL; MESSERSCHMIDT, 2013).

Após a aposentadoria, o professor Derci atuou em outros setores profissionais onde a mão de obra é tipificada como masculina. Trabalhou em vigilância de valores e, ainda, como vendedor de motos. No entanto, a escolha do professor, embora tenha ocorrido ao acaso, indica que foi nesse lugar que ele construiu sua carreira, mesmo que estejam presente estereótipos de gênero influenciando sua trajetória, no relacionamento entre homens e mulheres em relação à atuação profissional. Essa carreira permitiu a ele se estabelecer, mas que não seria outra escolha. Ao falar da carreira docente ele finaliza apontando que: "Olha eu penso 10 vezes antes (de voltar a atuar em sala de aula) que eu acho que eu não tenho paciência, não é que eu não goste, mas hoje eu acho que eu não teria paciência..." (DERCl, 2017).

A sensação de ter completado a carreira provoca o que Huberman (2007) explica como um desinvestimento profissional, no qual as pessoas se libertam, progressivamente, sem lamentar o investimento no trabalho, e passam a dedicar mais tempo a si próprias. Nesse período é comum o recuo frente às ambições e aos ideais presentes na partida. Porém, ele continua somando à sua história, e sua trajetória representa os modos como esteve na profissão e as relações que manteve com seus pares, pois, como ensina Elias (1994), a sociedade não existe sem indivíduos, bem como os indivíduos não existem sem a sociedade.

\section{CONSIDERAÇÕES FINAIS}

Este artigo é um recorte de uma pesquisa que permitiu perceber que a participação de homens na docência está para além da composição sexual do corpo preceptoral; significa avaliar todo um processo de profundas transformações sociais atribuída ao gênero dos indivíduos. Observar as construções das masculinidades na profissão docente contribui para a discussão e (re) significação de alguns conceitos que permearam e permeiam as práticas sociais, relacionais e educacionais, visto que elas permitem refletir na forma como os professores do sexo masculino receberam as tradições de uma profissão majoritariamente ocupada por mulheres, e de que forma os homens lidaram com a identidade profissional sexo tipificada, criada socialmente.

Mulheres e homens aprendem desde muito cedo a reconhecer seus lugares na sociedade, e é no âmbito da cultura e da história que se definem as identidades sociais, seja de gênero, sexuais, nacionais, raciais ou de classe. Os modelos inspiram processos sociais cotidianos, atribuindo às mulheres modos e gestos específicos, voltados a ações de delicadeza, graça, pudor, assuntos domésticos, trato com as crianças entre outros de ordem privada. Em contrapartida, aos homens se esperam gestos firmes, fala forte, aptidão física, força, comportamentos autoritários características que definem socialmente o espaço de atuação profissional de homens e mulheres.

A trajetória de vida de um professor homem nos permite compreender os aspectos de gênero envolvidos na profissão docente e, consequentemente,e nos grupos sociais específicos. Percebemos ainda as redes de interdependências que contribuem na construção das identidades masculinas e femininas, e os modos como tais modelos influenciam nos aspectos profissionais dos indivíduos. Assim, características socialmente 
atribuídas ao gênero podem interferir na escolha e atuação profissional onde estão presentes relações de poder entre os indivíduos nestes espaços de atuação.

Longe de finalizar a discussão sobre as relações de gênero na docência, ressaltamos que quando se reduz a responsabilidade da educação de crianças a atributos sócio construídos de gênero, deixamos de lado a capacitação profissional, que independentemente do sexo ou gênero, prepara o professor para exercer adequadamente as suas funções. A educação de crianças precisa ser realizada com trabalho reflexivo, formação inicial e continuada e muita reflexão, que permita desconstruir estereótipos.

\section{MALE TEACHING AND GENDER MEMORIES IN CHILDHOOD EDUCATION}

ABSTRACT: This article aims to verify and analyze the implications of the gender concept in the teacher's career of a teacher who taught for children in a space that was constituted mostly as female throughout the 20th century. The methodological option was thematic oral history producing a documentation from the memories of this teacher. The memories of the teaching trajectory will be analyzed in the light of Norbert Elias' theories and supported in the bibliography of the subject. This perspectives allow us to point in the school space, it was perceived ties of dependence, interdependence and power which are presente in the gender relations between teachers and their professional trajectories.

KEYWORDS: Male teachers. Teacher trajectory. Oral history. Norbert Elias.

\section{DOCENCIA MASCULINA Y MEMORIAS DEL GÉNERO EN LA EDUCACIÓN EN LA INFANCIA}

RESUMEN: El objetivo de este artigo, busca verificar y analizar las implicaciones del concepto del género en la trayectoria profesional de un profesor que ha lecionado para niños, en un espacio que se ha constituido mayormente como femenino a lo largo del siglo XX. La opción metodologica fue la Historia Oral tematica produziendo una documentación a partir de las memorias de este professor. Las memorias de la trayectoria docente serán analizadas a la luz de las teorias de Norbert Elias y apoyadas en la bibliografia tematica. Estas perspectivas nos permite en el espacio escolar, nos damos cuenta de las redes de dependencia, interdependencia y poder que están presentes en las relaciones de género envolviendo los docentes y sus trayectorias profesionales

PALABRAS CLAVE: Hombres profesores. Trayectoria docente. Historia oral. Norbert Elias. 
FARIA, A. H.; SARAT, M.; MONTIEL, L. W. T.

\section{NOTAS}

1) Pesquisa financiada recurso CAPES/FUNDECT.

2) Este trabalho faz parte de um projeto de pesquisa que discute as temáticas de gênero e educação na perspectiva de Norbert Elias.

3) Não negamos a importante reflexão acerca de outros gêneros e enfoques como a teoria queer, as transexualidades, os processos de generificação, no entanto, neste trabalho especificamente, utilizaremos homens e mulheres por serem docentes no período investigado.

4) Sobre História Oral citamos seus principais expoentes PORTELLI (2010), ALBERTI (2004), SEBE BOM MEIHY (1998), FERREIRA e AMADO (1998), POLLOK (1992) entre outros (vide bibliografia).

5) O Estado de Mato Grosso do Sul (MS) foi criado por meio da Lei Complementar $n^{\circ} 31$, de 11 de outubro de 1977, por desmembramento do antigo Mato Grosso, e foi implantado em $1^{\circ}$ de janeiro de 1979 (BRASIL, 1977).

\section{REFERÊNCIAS}

ALBERTI, V. Ouvir Contar: textos em história oral. Rio de Janeiro: Editora FGV, 2004.

BOSI, E. Memória e sociedade:lembranças de velhos. 7. ed. São Paulo: Companhia das Letras, 1994.

BRASIL. Decreto-Lei 6.141, de 28 de dezembro de 1943. Promulga a Lei Orgânica do Ensino Comercial. Disponível em: <http://www2.camara.leg.br/legin/fed/declei/19401949/decreto-lei-6141-28-dezembro-1943-416183-publicaçãooriginal-1-pe> . Acesso em 27 jul. 2017.

BRASIL. M.E.C. Lei $\mathrm{n} 05.692$, de 11 de agosto de 1971. Fixa diretrizes e bases para o ensino de 10 e $2^{\circ}$ graus, e dá outras providências. Diário Oficial da República Federativa do Brasil, Brasília, DF, 12 ago. 1971. Seção 1.

CARVALHO, M. P. de. Vozes masculinas numa profissão feminina. Rev. Estud. Fem., Florianópolis, v. 06, n. 02, p. 406-422. jul/dez. 1998.

CARVALHO, M. E. P.; RABAY, G. Gênero e educação superior: apontamentos so bre o tema. João Pessoa: Editora da UFPB, 2013.

CONNELL, R. Políticas da masculinidade. Educação e Realidade 20(5): p. 185-206, jul./dez. 1987.

.; MESSERSCHMIDT, J. W. Masculinidade hegemônica: repensando o conceito. Estudos feministas, vol. 21, n. 1, p. 241-282, 2013. 
Docência masculina e memórias de gênero...

Artigo 20

CRUZ, M. H. S. Mapeando diferenças de gênero no ensino superior da Universidade Federal de Sergipe. São Cristóvão: Editora UFS, 2012.

DEMARTINI, Z; ANTUNES, F. Magistério primário: profissão feminina, carreira masculina. Cadernos de Pesquisa, São Paulo, n. 86, p. 5-14, ago. 1993.

ELIAS, N. O processo civilizador: formação do Estado e civilização. v. 2. Rio de J aneiro: Zahar, 1993.

. A sociedade dos indivíduos. Org. por Michael Schöter. Tradução Vera Ribeiro. Rio de Janeiro: Jorge Zahar, 1994.

. Introdução à sociologia. Lisboa: Edições 70, 2005.

FARIA, A.H.; GONÇALVES, J.P. Educação Escolar e Relações de Gênero Segundo a Perspectiva de Homens Professores. Hispanista (Edição em Português), v. XVII, p. 1-11, 2016.

FERREIRA, M. M.; AMADO, J. (Org.). Usos e abusos da história oral. Rio de Janeiro: Fundação Getúlio Vargas, 1998.

FURTADO, A. C; MOREIRA, K. H. Professores leigos em escolas primarias no sul de Mato Grosso (1930-1970). Disponível em: <a href= http://www.anped.org.br/biblioteca/item/professores-leigos-em-escolas-ruraisprimarias-no-sul-de-mato-grosso-1930-1970> . Acesso em: 26 de julho de 2017.

GEBARA, A. Figurações e Educação: A escola, os jovens e os professores. In: SARAT, M; SANTOS, R. (Orgs.) Sobre Processos Civilizadores diálogos com Norbert Elias. $1^{\text {a }}$ ed. Dourados: Ed. UFGD, 2012. 330p.

HUBERMAN, M. O ciclo de vida profissional dos professores. In: NÓVOA, Antônio (org.) Vida de professores. 2a ed. Porto: Porto Editora, 2007, p. 31- 61.

LOURO, G. L. Mulheres na Sala de Aula. In: PRIORE. M. D.; PINSK. B. C. (Orgs.). História das Mulheres no Brasil. São Paulo: Contexto, 2012, p.441-481.

MEIHY, J. C. S. B. Manual de História Oral. 2. ed. São Paulo: Loyola,1998.

NÓVOA, A. Para um estudo sócio-histórico da gênese e desenvolvimento da profissão docente. Teoria \& Educação $\mathrm{n} \cong$ 4, 1991.

PIACENTINI. A. P. F. S. História da formação para professores leigos rurais: o curso de magistério rural em Dourados na década de 1970. Dissertação (Mestrado em Educação) - Universidade Federal da Grande Dourados. Dourados. 2015. 
FARIA, A. H.; SARAT, M.; MONTIEL, L. W. T.

PINCINATO, D. A. V. Homens e masculinidades na cultura do magistério: uma escolha pelo possível, um lugar para brilhar (São Paulo, 1950-1989). Tese. (Doutorado em Educação) - Universidade de São Paulo. São Paulo, 2007.

POLLAK, M. Memória e identidade social. Estudos Históricos, Rio de Janeiro, v. 5, n. 10, p. 200-2012, 1992.

PORTELLI, A. Ensaios de história oral. São Paulo: Letra e Voz, 2010. 258p.

PROVÍNCIA de Mato Grosso. Inspetoria Geral dos Estudos. Relatório do inspetor, Dermevil José dos Santos Malhado, de 17 de agosto de 1880. Publicado como Anexo C do relatório do presidente da Província Barão de Maracajú de 1880. Cuiabá:Tipografia de Joaquim J. R. Calháo, 1880.

RABELO, A. O. Professores Discriminados: um estudo sobre os docentes do sexo masculino nas séries do ensino fundamental. São Paulo. Educação Pesquisa, v. 39, n. 4, p. out./dez. 2013, p. 907-925.

RAMOS, J. Um estudo sobre os professores homens da educação infantil e as relações de gênero na Rede Municipal de Belo Horizonte - MG.2011, 139 f. Tese (Doutorado em Educação) - Pontifícia Universidade Católica de Minas Gerais, PUC/MG.

SAYÃO, D. Relações de gênero e trabalho docente na educação infantil: um estudo de professores em creche. Tese (Doutorado em Educação) - Programa de Pós-Graduação em Educação, Universidade Federal de Santa Catarina, Santa Catarina, 2005.

SARAT, M. Histórias de estrangeiros no Brasil: infância, memória e educação. Tese (Doutorado em Educação) - Unimep, Piracicaba, 2004.

. História da formação de professoras para a infância: experiências no Brasil e na Ärgentina. Teoria e Prática da Educação, v. 18, p. 23 (B1)-35, 2015.

;CAMPOS, M. I. Memórias da Infância e da Educação: abordagens eliasianas sobre as mulheres. Educação e Realidade Edição eletrônica, v. 42, p. 1257-1277, 2017.

.; SANTOS, R. História Oral como fonte: Apontamentos metodológicos e técnicos da pesquisa. In: COSTA, J. C.; MELO, J. J. P.; FABIANO, L. H.; (Orgs.). Fontes e Métodos em História da Educação. Dourados: UFGD, 2010, p.49-78.

SCOTT, J. Gênero: uma categoria útil de análise histórica. Educação e realidade, Porto Alegre, v. 2, n. 20, jul./dez. 1998, p. 71-99.

TAMBARA, E. Problemas teórico-metodológicos da História da Educação. IN : SAVIANI, D. (Org). História e História da Educação - o debate teórico metodológico atual. Campinas: Autores Associados, 1998, p. 79- 87. 
Docência masculina e memórias de gênero...

Artigo?42

TANURI, L. M. História da formação de professores. Revista Brasileira de Educação, n. 14, p. 61-88, mai./jun./jul./ago. 2000.

THOMPSON, P. A voz do passado. São Paulo: Paz e Terra, 1992.

VICENTINI, P. P; LUGLI, R. G. História da Profissão Docente no Brasil: representações em disputa. São Paulo: Cortez Editora, 2009, 234p.

\begin{abstract}
Adriana Horta de Faria: Graduada em Pedagogia pela Universidade Federal de Mato Grosso do Sul. Mestranda do Programa de Pós-Graduação em Educação, pela Universidade Federal da Grande Dourados/UFGD, na linha História, Memória e Sociedade. Integrante do Grupo de Pesquisa "Educação e Processo Civilizador" (GPEPC). OrCID: http://orcid.org/0000-0003-0116-4640

E-mail: adrianahortadefariafaria@yahoo.com.br
\end{abstract}

Magda Sarat: Professora Magda Sarat Doutora em Educação. Professora associada da Faculdade de Educação na Universidade Federal da Grande Dourados. Docente do Programa de Pós-Graduação da Universidade Federal da Grande Dourados, Mestrado e Doutorado. Líder do Grupo de Pesquisa Educação e Processo Civilizador.

E-mail: magdaoliveira@ufgd.edu.br

Larissa Wayhs Trein Montiel: É professora Assistente na Universidade Federal de Mato Grosso do Sul, campus Naviraí, pesquisadora do Grupo de Estudos e Pesquisa em Prática Educativa e Tecnologia Educacional - GEPPETE- sendo líder da Linha de Pesquisa Práticas Educativas e Formação Docente. Graduada em Pedagogia pela Universidade Federal da Grande Dourados no ano de 2007, Mestrado em Educação (2010) e Doutoranda (2015) do Programa de Pós-Graduação em Educação na linha de História da Educação, Memória e Sociedade, na Universidade Federal da Grande Dourados. Atua principalmente nos seguintes temas: História da Educação, Formação de Professores e Práticas Educativas na Educação Infantil e Ensino Fundamental.

E-mail: larissawtmontiel@hotmail.com

Este periódico utiliza a licença Creative Commons Attribution 3.0, para periódicos de acesso aberto (Open Archives Iniciative - OAI). 